\title{
$O$ adoecimento do professor frente à violência na escola ${ }^{\star}$
}

\author{
Marilda Gonçalves Dias Facci (D) $\star \star$ \\ Universidade Estadual de Maringá, Paraná, PR, Brasil
}

\begin{abstract}
Resumo
A violência na escola tem sido um tema recorrente nos noticiários de jornais. Professores são agredidos por alunos; socos, pontapés, depredação do patrimônio público são desfilados na mídia, fazem parte do dia a dia das instituições de ensino e demandam o olhar da Psicologia. Neste contexto, o objetivo deste artigo é apresentar os resultados de uma pesquisa realizada com professores sobre a questão do adoecimento do professor provocado pela violência na escola. Participaram do estudo 31 professores do ensino fundamental de uma cidade do norte do Paraná. As informações foram obtidas por meio de um questionário aplicado a 21 professores e de entrevistas com dez professores que se encontravam readaptados. Concluiu-se que, embora a violência física e verbal esteja presente na escola, os professores analisam que o adoecimento está vinculado ao acirramento das condições de trabalho vivenciado na atualidade, havendo, segundo os pressupostos da Psicologia Histórico-Cultural, uma cisão entre sentido e significado na atividade docente.
\end{abstract}

Palavras-chave: violência na escola; adoecimento; Psicologia Histórico-Cultural.

\section{Teacher's illness due to violence in school}

\begin{abstract}
Violence in the school is a recurring theme in newspapers. Teachers punched and kicked by students and damage to the school premises are constant news in the media. They are daily occurrences and should be focused by Psychology. Current paper presents results from a research work with teachers' illnesses due to violence in the school. Thirty-one primary school teachers from the northern region of the state of Paraná, Brazil, participated. Data were harvested by a questionnaire sent to 21 teachers; interviews with ten readapted teachers were performed. Although physical and verbal violence is present in the school, teachers state that illnesses are linkedto the intensification of working conditions experienced on a daily basis. According to Historical and Cultural Psychology, there is a gap between feeling and meaning in the teaching activity.
\end{abstract}

Keywords: violence in the school; illness; Historical and Cultural Psychology.

A violência na escola tem sido um tema recorrente nos noticiários de jornais. A mídia noticia quase diariamente casos de acertos de contas de gangues nas escolas, professoras agredidas por alunos, alunos assassinados dentro da escola, socos, pontapés e depredação do patrimônio público. Vandalismo contra os bens públicos e contra os professores, indisciplina, desrespeito, bullying, uso e tráfico de drogas, policiais chamados à escola para lidar com diversas ocorrências, como o desacato a professores ou entre os alunos, entre outros acontecimentos - são casos que fazem parte do dia a dia no interior das instituições de ensino e demandam o olhar da Psicologia no âmbito escolar.

Merece destaque um episódio de violência, ocorrido no dia 29 de abril de 2015, contra os servidores públicos no Paraná - entre eles, os professores -, os quais, em defesa de seus direitos, garantidos na trajetória histórica, foram agredidos, conforme várias imagens difundidas no Estado do Paraná, no Brasil e no mundo. O direito democrático de manifestar posição contrária a mudanças no sistema de previdência do Paraná que envolvem a garantia de aposentadoria de todo o funcionalismo público do Estado foi negado e enfrentado, não com o diálogo, mas com atos de violência. Com toda essa situação, fica

\footnotetext{
^Fonte de Financiamento: Fundação Araucária de Apoio ao Desenvolvimento Científico e Tecnológico do Estado do Paraná.

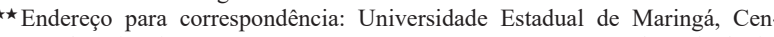
tro de Ciências Humanas Letras e Artes, Departamento de Psicologia Avenida Colombo, 5790 - Jardim Universitário - Maringá, PR - Brasil. CEP: 87020900.E-mail:madfacci@uem.b.

Os dados completos da autora encontram-se ao final do artigo.
}

evidente que governantes como estes do Estado do Paraná pouco valorizam o trabalho do professor, fato que influencia o trabalho destes profissionais.

A violência contra professores é notória no país e no mundo. No dia 15 de outubro de 2014, o Jornal do Brasil apresentou a seguinte manchete: "Brasil lidera ranking de violência contra professores". A reportagem trazia dados preocupantes de pesquisa realizada pela Organização para a Cooperação e Desenvolvimento Econômico (OCDE), que é composta por 35 países e compara aspectos econômicos e também sociais e educacionais, por exemplo, e pesquisou sobre índices de violência na escola. Por meio desta Organização foi realizado um estudo em nível mundial com 100 mil professores e diretores de escolas do segundo ciclo do ensino fundamental e do ensino médio (alunos de 11 a 16 anos) de 34 países. No Brasil, responderam ao questionário 14.291 professores e 1.057 diretores de 1.070 escolas. Os investigadores chegaram aos seguintes dados: " $12,5 \%$ dos professores entrevistados no país afirmaram ser vítimas de agressões verbais ou de intimidação de alunos pelo menos uma vez por semana", enquanto que a média entre os 34 países é de 3,4\%" (BRASIL lidera..., 2014, p. 1).

Os dados também revelaram que $12,6 \%$ dos entrevistados sentiam-se desvalorizados profissionalmente, ao passo que a média global é de $31 \%$. Os salários dos profissionais entrevistados em nível mundial é o triplo do que é pago no Brasil. A pesquisa indicou ainda que, “[...] apesar dos problemas, a grande maioria dos professores no mundo se diz satisfeita com o trabalho" (BRASIL li- 
dera..., 2014, p. 1). Com base nesses dados, entendemos que o sentimento de desvalorização pode estar relacionado à própria desvalorização do trabalho do professor brasileiro, que sofre agressão, sim, conforme vimos nesta pesquisa, e que, além disso, tem um salário bem menor do que os professores de outros países.

O processo ensino-aprendizagem mostra-se permeado pela afetividade, que envolve sentimentos tanto de satisfação em relação ao ensinar e aprender quanto de frustração, baixa autoestima e tristeza - sentimentos que levam ao sofrimento psíquico tanto do professor como do aluno. No caso do aluno tem-se discutido principalmente o bullying, e no caso do professor a literatura traz termos como mal-estar docente e síndrome de burnout para expressar o sofrimento/adoecimento do professor na sua atividade profissional.

Violência e sentimento de desvalorização permeiam a prática pedagógica de uma considerável parcela de professores e muitas vezes causam adoecimento. É sobre esse ponto que discorreremos neste texto. Nosso objetivo é apresentar os resultados de uma pesquisa realizada com professores sobre a temática do adoecimento do professor causado pela violência na escola. Inicialmente, ao falarmos da violência na escola, abordaremos o adoecimento dos professores sob os pressupostos da Psicologia Histórico-Cultural, e finalizaremos o texto trazendo dados da pesquisa de campo realizada com professores.

\section{A violência na escola e o adoecimento do professor}

Sposito (2001) faz um balanço das pesquisas realizadas no Brasil, de 1980 até 1998, sobre as relações entre a violência e a escola, a partir de um diagnóstico quantitativo em torno do tema e utilizando dissertações e teses publicadas na pós-graduaçao em Educação. A autora identifica que as produções teóricas traziam como as duas principais modalidades de violência: 1- ações contra o patrimônio - mais direcionadas para a estrutura física da escola, por meio de depredações e pichações; 2a agressão interpessoal, principalmente aquela praticada entre os alunos. Naquele momento, segundo a autora, o tema da violência escolar ainda era pouco estudado, pois ela identificou, dentre os 8.667 trabalhos, que apenas nove investigavam a violência na escola, ${ }^{1}$ o que denota a necessidade de mais pesquisas sobre essa temática.

Existem várias possibilidades de compreender a violência, a partir de diversos fundamentos teóricos. Debarbieux (2001) afirma que definir a violência na escola é, antes de tudo, mostrar como ela é socialmente construída. Charlot (2002) faz a distinção entre três conceitos de violência: violência na escola, violência da escola e violência contra a escola. A "violência na escola" é aquela que se produz dentro do espaço escolar, mas não tem vinculação direta com as atividades que ocorrem neste espaço - por exemplo, alunos da comunidade entrarem na escola para acertar contas de desavenças que ocorrem fora da instituição, sendo a escola apenas o local onde as

\footnotetext{
${ }^{1}$ Quando fizemos um levantamento na base SciELO, no mês de fevereiro do ano de 2015, utilizando os descritores "violência" e "escola", também localizamos 264 indicações de artigos. Refinando mais e acrescentando a essas palavras o termo "professor", encontramos somente seis artigos.
}

brigas acontecem. A "violência contra a escola" remete à instituição e àqueles que a representam - por exemplo, depredação da escola, insultos aos professores e funcionários. A "violência da escola" é compreendida pelo autor como "[...] uma violência institucional, simbólica, das relações de poder entre professores e alunos, além de atos considerados pelos alunos como injustos ou racistas" (CHARLOT, 2002, p. 435).

No caso deste artigo, quando mencionamos "violência na escola" estamos entendendo, diferentemente de Charlot, a violência que se remete à instituição e à comunidade escolar, assim como à forma como as relações são estabelecidas no cotidiano escolar.

Abramovay e Rua (2002) entendem que para compreender e explicar a violência na escola é necessário analisar aspectos relativos tanto ao espaço intraescolar como ao extraescolar, bem como as características das vítimas e dos agressores e as diferentes instituições e ambientes que os alunos frequentam. Entre as variáveis exógenas, as autoras citam as seguintes:

[...] questões de gênero (masculinidade/feminilidade); relações raciais (racismo, xenofobia); situações familiares (características sociais das famílias); influência dos meios de comunicação (rádio, TV, revistas, jornais, etc.); espaço social das escolas (o bairro, a sociedade). [Entre as endógenas tem-se:] [...] a idade e a série ou nível de escolaridade dos estudantes; as regras e a disciplina dos projetos pedagógicos das escolas, assim como o impacto do sistema de punições; o comportamento dos professores em relação aos alunos e a prática educacional em geral (ABRAMOVAY; RUA, 2002, p. 25).

Charlot (2002), neste aspecto, considera que se deve dar uma grande atenção à relação entre violência e o saber, além de considerar como a sociedade está organizada, as formas de dominação, a desigualdade e ainda as práticas cotidianas de ensino.

Cumpre observar que essa violência não é um problema da atualidade, ela tem suas características constituídas historicamente, a partir da forma como os homens se organizam na prática social, na materialidade das relações sociais, conforme propõe Silva (2006).

Chauí (2000, p. 432), ao abordar a relação entre ética e violência, afirma:

Evidentemente, as várias culturas e sociedades não definiram e nem definem a violência da mesma maneira, mas, ao contrário, dão-lhe conteúdos diferentes, segundo os tempos e os lugares. No entanto, malgrado as diferenças, certos aspectos da violência são percebidos da mesma maneira, nas várias culturas e sociedades, formando o fundo comum contra o qual os valores éticos são erguidos. Fundamentalmente, a violência é percebida como exercício da força física e da coação psíquica para obrigar alguém a fazer alguma coisa contrária a si, contrária aos seus interesses e desejos, contrária ao seu corpo e à sua consciência, causando-lhe danos profundos e irreparáveis, como a morte, a loucura, a autoagressão ou a agressão aos outros.

Para a autora, no Brasil, a violência é entendida como o uso da força física e do constrangimento psíquico que leva alguém a agir de forma contrária a sua vontade. "A 
violência é a violação da integridade física e psíquica, da dignidade humana de alguém" (CHAUÍ, 2000, p. 432). Ocorre, neste sentido, uma transformação da pessoa em objeto, uma transgressão aos direitos humanos da pessoa.

Sánchez Vázquez (1977, p. 381), por sua vez, afirma que a violência altera uma legalidade natural e social e que, para essa destruição, os homens usam da força física ou de ações que violam a vida psíquica, com o " [...] objetivo de manter um domínio econômico e político, ou de conseguir esses ou aqueles privilégios". Isto significa que o uso da violência está relacionado à propriedade privada, à divisão de classes e às contradições entre classes antagônicas na busca por manter o que foi conquistado - em outras palavras, à falta de igualdade de acesso aos bens materiais e culturais produzidos pelos homens. Como a violência e a não violência estão em constante movimento, não podemos naturalizar esse fenômeno, nem individualizá-lo, ou seja, não podemos buscar no professor, nos alunos ou na família a culpa por esse problema. A questão deve ser considerada estrutural, não se culpando uma parcela da sociedade. Em muitos episódios de violência na escola constata-se que a culpa acaba ficando nos ombros do aluno, dos pais e dos professores, sem que se faça uma análise dos aspectos histórico-sociais que permeiam atos de violência no espaço da escola e interferem na tarefa desta de socializar os conhecimentos, conforme apregoa Saviani (2003) em relação à função social da escola. Condições objetivas como falta de investimento financeiro para a educação, precarização do trabalho, baixos salários, formação inicial de baixa qualidade, falta de políticas educacionais direcionadas a formação continuada dos professores, falta de estrutura física adequada para a atividade pedagógica, entre outros aspectos, falta de acesso igualitário ao conhecimento pela classe trabalhadora, são condições objetivas que influenciam o cotidiano da escola e podem estar atrelados à violência na escola. Fala-se de violência, mas não se busca entender por que a violência presente na sociedade acaba invadindo o espaço escolar.

Heller (1994) também caminha nessa linha de raciocínio. Os seus estudos centram-se na discussão sobre instinto, agressividade e caráter, tomando como referência ideias marxistas, e destacam que na sociedade impera a competitividade, a luta de classes, de modo que a agressividade (no nosso caso, a violência) é um modo de tornar normal a estrutura da sociedade na forma em que se encontra. A autora compreende que o homem sofre diante de sua incapacidade de realização e, como não consegue sentir-se seguro, reage às situações postas como impulsos em forma de ira contra o outro:

Nossos impulsos e motivos tomam a forma de ira dirigida à degradação ou aniquilação de outros homens porque somos pessoas particulares, porque não possuímos segurança no próprio eu nem amor próprio fundado em nós mesmos, porque não conseguimos realizar nossas capacidades e sofremos por isso (HELLER, 1994, p. 191-192). ${ }^{2}$

As traduções do espanhol para o português, nesta e nas demais citações apresentadas neste artigo, foram realizadas pela autora.
Nas relações de classe estabelecidas no sistema capitalista, apenas uma parcela dos homens se autorrealiza, porque o homem busca o amor próprio naquilo que possui, e não em sua personalidade, tornando-se frustrado em suas tentativas.

A sociedade se baseia na divisão de trabalho. [...] A atividade central dentro da divisão social do trabalho, ou no trabalho mesmo, só significa autorrealização para uma minoria de homens cada vez mais reduzida. [...] A base do amor próprio não deve ser buscada pelo homem mesmo, em sua personalidade, senão no que possui: na propriedade. Entretanto, isto é só um quase-amor próprio, que não pode proporcionar ao homem um sentimento de segurança. $\mathrm{O}$ homem bloqueado em seu desenvolvimento, que tem que buscar a si mesmo fora de si, possui, como já visto, uma afinidade com a agressividade (HELLER, 1994, p. 199).

A autora conclui que a agressividade se deve às condições de vida que o sistema capitalista nos impõe. Essas condições podem provocar atos de violência nas relações estabelecidas na escola, os quais, conforme o posicionamento de Abramovay e Rua (2002), acabam trazendo prejuízos para o desenvolvimento acadêmico e pessoal. Muitos professores abandonam a profissão em decorrência das violências e da falta de reconhecimento de seu trabalho.

Silva (2006, p. 22), em concordância com essa ideia, entende que a violência escolar agrava os problemas enfrentados na escola e

[...] evidencia, dentro da instituição escolar, a exclusão social a que muitos brasileiros estão sujeitos. Porque, a grande maioria das vítimas ou perpetradores da violência dentro das escolas, são também vítimas de um sistema social excludente. A violência na escola tem dificultado que muitos educandos se apropriem dos conteúdos social e historicamente elaborados, ao serem expulsos das salas de aula, pelo motivo de participação em brigas.

Os atos de violência na escola acabam colocando uma pesada responsabilidade nos ombros dos professores, que no dia a dia têm que fazer enfrentamentos em relação a isso e que apresentam várias formas de conceituar tal realidade. Conforme veremos a seguir, já foram feitas diversas pesquisas sobre a visão que os professores têm sobre a violência na escola.

Lobato e Placco (2007), em entrevista realizada com professores, e Loureiro e Queiroz (2005), em pesquisa realizada com a equipe pedagógica, os auxiliares de disciplina e um grupo de estudantes de uma escola particular, constaram que, na concepção dos entrevistados, a violência pode ser tanto física como verbal. Constataram também que, na opinião dos professores, as causas da violência na escola são decorrentes, principalmente, da desestruturação familiar. Por sua vez, Lobato e Placco (2007) concluíram que a estrutura socioeconômica foi outra variável apresentada pelos pesquisados, que veem a violência como consequência das precárias condições financeiras e materiais pelas quais passam os alunos. Além disso, professores também trazem algumas características estruturais da escola como promotoras de violência.

Fractal, Rev. Psicol., v. 31 - n. 2, p. 130-142, 2019 
Lobato e Placco (2007), ao investigarem as formas de enfrentamento da violência, constataram que o diálogo foi a estratégia mais citada pelos professores; porém, no caso de agressão física grave, os professores encaminham os alunos para a direção da escola para que esta entre em contato com os pais ou responsáveis dos alunos. O Conselho Tutelar só é acionado quando o acontecimento extrapola a possibilidade de resolução na escola. Outra conclusão a que as autoras chegaram foi a de que, dos dezesseis entrevistados, “[...] quinze afirmam que a violência escolar cotidiana interfere na qualidade do seu trabalho, e todos acreditam que tal fenômeno interfere negativamente no aprendizado dos alunos (LOBATO; PLACCO, 2007, p. 84).

Anser, Joly e Vendramini (2003), ao pesquisarem sobre a temática da violência na escola junto a 127 professores dos ensinos fundamental, médio e universitário das redes particular e pública do interior paulista, chegaram à conclusão de que o conceito de violência, assim como os aspectos que contribuem para sua incidência, relaciona-se diretamente à violência social. Os professores elencaram os valores, as relações humanas estabelecidas e os aspectos socioeconômicos como categorias que determinavam as causas de violência.

Outro estudo que gostaríamos de relatar é o realizado por Gomes e Pereira (2009), que investigaram as percepções dos licenciados a respeito das violências e de seu próprio preparo em grupos focais compostos de dez a 12 participantes, a maioria deles com experiência docente. Essa violência, segundo os professores, pode ser tanto física como simbólica, e ocorre como reflexo das famílias e dos bairros nos quais os alunos vivem. Segundo a análise dos autores, há uma íntima associação entre a carência, a pobreza, a exclusão social e os vários tipos de violência. Além disso, outro motivo apresentado foi a relação estabelecida com os colegas, que no grupo “[...] construíam padrões de conduta antissocial, envolvendo-se com a criminalidade, inclusive o uso e o tráfico de drogas, e praticando-a nos arredores ou no interior da escola. Quem não aceita os códigos está fora e sozinho, vulnerável aos ataques" (GOMES; PEREIRA, 2009, p. 214). Outro motivo mencionado foi a violência da própria escola, representada pelo comportamento de professores que não respeitavam os alunos. Os autores ponderam que a escola reflete as relações de violência da sociedade capitalista, e fazem a seguinte afirmação: "Nota-se que os fatores extraescolares ocuparam uma posição notável na descrição, em detrimento dos fatores intraescolares, secundarizados pelos participantes" (GOMES; PEREIRA, 2009, p. 214). Em sua análise, observam que também parece haver certa tendência do professor a culpar o aluno pelo fracasso, considerando as origens sociais e descartando a sua culpa enquanto aquele que ensina. Os autores chegaram à conclusão de que os professores se sentem despreparados para lidar com a violência na escola. Tal fato, segundo os autores, agrava as tensões e pode provocar o adoecimento do professor.

Santos (2014) realizou uma pesquisa na base de dados SciELO, com o objetivo de analisar como o adoecimento e o sofrimento estão sendo compreendidos na produção científica. Em um primeiro momento, foram localizados
28 artigos, mas, após uma leitura inicial, o pesquisador identificou somente 14 que enfatizavam o adoecimento psíquico. Doze trabalhos $(85,7 \%)$ relacionam o adoecimento do professor com as condições do local de trabalho em que ele está inserido e o modo como este local está organizado. Destes, sete trabalhos (50\% dos artigos encontrados) tematizaram o adoecimento psíquico do professor abordando a síndrome de burnout, tanto em estudos elaborados a partir de pesquisas bibliográficas como de estudos de campo e pesquisa experimental.

Quanto à síndrome de burnout, os autores Codo (1999), Benevides-Pereira et al. (2008), em pesquisas realizadas com professores, identificaram que muitos deles apresentam sintoma desta síndrome. Esteve (1999), Mosquera e Stobäus (1996) também tratam do mal-estar docente que é "[...] causado pela falta de apoio da sociedade aos professores, tanto no terreno dos objetivos do ensino como nas compensações materiais e no reconhecimento do status que se lhes atribui" (MOSQUERA; STOBÄUS, 1996, p. 141). Na análise dos autores, os professores são influenciados na sua vida pessoal, e assim acabam sentindo-se sobrecarregados de trabalho e condenados a ter um desempenho insatisfatório na docência.

De forma geral, segundo Santos (2014), os determinantes que contribuem para o mal-estar, a síndrome de burnout e o adoecimento do professor, nas pesquisas, podem ser elencados da seguinte forma: falta de reconhecimento da função do professor; falta de respeito dos alunos, dos governantes e da sociedade em geral; baixos salários; diminuição dos espaços de discussão coletiva; tripla jornada; sobrecarga de trabalho; baixa participação direta na gestão e planejamento do trabalho; culpabilização dos alunos pelos resultados negativos; invasão do espaço domiciliar; inclusão de crianças com deficiências em classes de ensino regular, dentre outros. $\mathrm{O}$ autor pondera que a reestruturação produtiva e as reformas educacionais, nos últimos anos, têm contribuído para o aumento do adoecimento dos professores.

O estudo de Assunção e Oliveira, D. (2009) corrobora as conclusões de Santos (2014). Segundo os autores, a intensificação do trabalho nas escolas, fundamentada na implantação de reformas educacionais desde a década de 1990, tem também contribuído para o adoecimento do professor, para essa sensação de mal-estar diante das tarefas cotidianas na sala de aula. As demandas são enormes e os professores querem cumprir sua tarefa com qualidade, mas não têm condições objetivas, o que, segundo as autoras, provoca adoecimento nessa classe de trabalhadores.

Também Silva (2006), ao analisar o trabalho docente em uma escola municipal, apresenta duas pesquisas que retratam o crescente aumento da síndrome de burnout e sua relação com as condições de trabalho dos docentes. A autora comenta que os professores estão perdendo o sentido do trabalho e sentindo-se impotentes para torná-lo mais significativo. O trabalho não material realizado pelo professor tem sido permeado pelas mesmas características do trabalho de forma geral - ou seja, o estranhamento em relação ao próprio trabalho e a si mesmo. Nas pesquisas analisadas, a autora conclui que as condições precárias de 
trabalho e a falta de perspectivas profissionais têm contribuído para o abandono da profissão. O profissional sente um distanciamento da atividade docente e acaba não se envolvendo com o trabalho. Segundo Silva (2006, p. 96),

A reestruturação produtiva e as reformas neoliberais em curso, no campo educativo, representam mudanças que tendem a contribuir para a ampliação do burnout, em consequência da crescente precarização do trabalho do professor. As questões suscitadas pelas abordagens contempladas neste artigo sinalizam a necessidade de se ultrapassar a descrição da síndrome da desistência como fenômeno crescente entre os professores. Sugerem que também examinemos possibilidades de resistência a um modelo econômico-político-social que, cada vez mais, precariza os trabalhadores em todo o mundo e, em particular, neste país.

Em uma sociedade na qual os trabalhadores são massificados no trabalho, por influência dos preceitos neoliberais, da reestruturação produtiva e das reformas que vêm ocorrendo na educação, conforme Santos (2014), os professores são cobrados a responder a questões que vão muito além da sua formação, o que provoca um sentimento de "desprofissionalização", de falta de identidade profissional. Oliveira, D. (2004), assim como Santos, compreende que as reformas educacionais iniciadas a partir dos anos 1990 têm trazido mudanças profundas na natureza do trabalho do professor. Neste contexto ocorre uma desqualificação do trabalho do professor, resultando na perda de seu direito de participar na organização do seu trabalho, o que contribui para a sensação de mal-estar.

Oliveira, D. (2004, p. 1140) faz a seguinte síntese:

O que temos observado em nossas pesquisas é que os trabalhadores docentes se sentem obrigados a responder às novas exigências pedagógicas e administrativas, contudo expressam sensação de insegurança e desamparo tanto do ponto de vista objetivo - faltam-lhes condições de trabalho adequadas - quanto do ponto de vista subjetivo.

Entre essas demandas podemos citar a violência na escola, que reflete a violência da sociedade, e mesmo a violência contra o professor, que vê seu trabalho e sua remuneração tornarem-se precários. O desgaste e a insatisfação com o trabalho acabam provocando adoecimento no professor.

Facci (2004) também entende que atualmente o trabalho do professor vem sendo esvaziado. Em consequência de políticas educacionais calcadas em teorias pedagógicas e psicológicas que secundarizam a intervenção do docente e desvalorizam o ensino de conhecimentos científicos, os professores podem sofrer um processo de alienação, em decorrência da ruptura entre sentido e significado da atividade docente, conforme entende Leontiev (1978a, 1978b), o que pode contribuir para o adoecimento do professor e influir na sua personalidade, conforme veremos a seguir.

\section{Alguns apontamentos sobre o sofrimento e adoecimento} dos professores com base na Psicologia Histórico-Cultural

O desenvolvimento da personalidade, na perspectiva da Psicologia Histórico-Cultural, abarca o natural, o histórico no ser humano, e é um conceito social. A personalidade não é inata, ela surge como resultado do desenvolvimento cultural, e o sofrimento do professor provoca alterações na estruturação da sua personalidade e na forma como realiza o seu trabalho, decorrente das relações estabelecidas na sociedade. A proposta do Materialismo Histórico e Dialético de estudar o homem a partir de seu caráter social e histórico - em que o humano provém de sua vida em sociedade em meio à cultura criada pela humanidade, sendo produto e produtor de sua história (ser passivo e ativo) - vem ao encontro da proposta de estudo das emoções como processos psicológicos construídos e significados de acordo com seu caráter sócio-histórico. Com base nessa ideia, é possível entender que o fenômeno da violência e do adoecimento do professor não é individual, intrínseco ao indivíduo, e que, como todos os comportamentos, deve ser analisado a partir da relação dialética entre objetividade (condições materiais de trabalho, investimento financeiro na educação, salário, infraestrutura da escola, formação de professores, entre outros fatores) e subjetividade.

Conforme a análise de Sève (1979), feita a partir de um referencial baseado nos estudos de Marx, o homem é a síntese das relações sociais, de relações que vão além da intersubjetividade e estão atreladas às relações de classe. Assim, a personalidade do homem é formada de acordo com as condições histórico-sociais em que ele vive, portanto não nasce determinada por fatores biológicos.

Leontiev (1978b, p. 140) também apresenta essa ideia, e entende que a personalidade é criada pelas relações sociais estabelecidas pelo indivíduo em sua atividade e é determinada "[...] pela natureza das próprias relações que a engendram; se trata das relações sociais específicas do homem, nas quais este entra em sua atividade objetivada". O conjunto das atividades realizadas pelos homens é que constitui sua personalidade. Para explicar a personalidade é "preciso partir do desenvolvimento da atividade, de seus tipos e formas concretas, e dos vínculos que se estabelecem entre eles [...]" (LEONTIEV, 1978b, p. 145).

No entanto, essa eleição pode ocorrer diante de posições sociais antagônicas, que se apresentam nos significados. As atividades são mediadas pelos significados e sentidos. Leontiev (1978a, p. 95) faz a seguinte afirmação sobre o significado (ou significação) social:

É a forma ideal, espiritual da cristalização da experiência e da prática sociais da humanidade. [...] A significação pertence, portanto, antes de mais nada, ao mundo dos fenômenos objetivamente históricos. [...] No decurso da sua vida, o homem assimila a experiência das gerações precedentes; este processo realiza-se precisamente sob a forma da aquisição das significações e na medida desta aquisição. A significação é, portanto, a forma sob a qual um homem assimila a experiência humana generalizada e refletida.

Leontiev (1978a) entende como sentido pessoal aquilo que faz parte do indivíduo, que é apropriado a partir das significações sociais. $\mathrm{O}$ autor explica que o sentido

[...] é antes de mais nada uma relação que se cria na vida, na atividade do sujeito. Esta relação específica estabelece-se no decurso do desenvolvimento da atividade. [...] De um 
ponto de vista psicológico concreto, este sentido consciente é criado pela relação objetiva que se reflete no cérebro do homem, entre aquilo que o incita a agir e aquilo para o qual a sua ação se orienta como resultado imediato. Por outras palavras, o sentido consciente traduz a relação do motivo ao fim (LEONTIEV, 1978a, p. 98).

O sentido remete à forma como essa significação é dada à realidade pelo indivíduo. Leontiev (1978b) assevera que o sentido está relacionado ao motivo que lhe corresponde e está vinculado com o fim da atividade. De acordo com o autor, no processo de alienação que ocorre nas relações de trabalho existe uma ruptura entre o sentido e o significado.

Essa atividade possui uma estrutura geral composta de necessidade, motivo e ação. É a necessidade que desencadeia as atividades, e estas são compostas de operações. Na formação da personalidade existem relações hierárquicas das atividades que a caracterizam. No desenvolvimento do indivíduo algumas atividades vão se subordinando a outras. Para Leontiev (1978b), as atividades são guiadas por motivos, nos quais está objetivada alguma necessidade. Essa hierarquização ocorre em todas as fases do desenvolvimento. O motivo é aquilo que incita à ação, que dirige a atuação para satisfazer a uma determinada necessidade. Para o autor, existem "motivos geradores de sentido" e "motivos-estímulos". Aqueles se referem aos motivos que impulsionam a atividade e tem um sentido pessoal; estes impulsionam a ação, mas não dão origem ao sentido.

De acordo com Leontiev (1978b), a necessidade orienta e regula a atividade concreta do sujeito na realidade. Ela é um fator desencadeador da atividade. "Toda atividade do organismo está dirigida a satisfazer as necessidades naquilo que lhes é indispensável para prolongar e desenvolver sua vida" (LEONTIEV, 1969, p. 341). A necessidade é o que motiva o sujeito a ter objetivos e a realizar ações para supri-la. Para Leontiev (1978b), essas ações são realizadas por várias operações. A ação é o componente principal de algumas atividades. A operação é a forma que utilizamos para realizar a ação: por exemplo, a nossa ação é decorar um poema; a operação pode ser copiá-lo várias vezes, recitá-lo, etc. Uma ação se torna atividade quando o motivo está relacionado com a finalidade proposta. As atividades estão em constante processo de transformação.

Leontiev (1978b) afirma que as bases para a formação da personalidade estão vinculadas à riqueza dos vínculos do indivíduo com o mundo, às condições históricas concretas em que os vínculos se estabelecem e ao grau de hierarquização de suas atividades e de seus motivos. Muitas relações que os homens estabelecem com a realidade são objetivamente contraditórias, e isso permeia a formação da personalidade do homem.

Zeĭgarnik (1979) propõe uma possibilidade de investigação sobre as patologias psíquicas a partir da atividade do sujeito, considerando seus motivos e necessidades constituídos nas suas relações objetivas de vida e trabalho. A autora compreende que a enfermidade mental lesiona a personalidade como um todo:
Falamos de mudanças na personalidade quando, por influência da enfermidade, se estreitam no paciente os interesses, diminuem as necessidades, quando retorna indiferente em direção que antes lhe inquietava, quando suas ações perdem sua finalidade, quando seus atos se fazem ilógicos, quando o homem deixa de regular sua conduta e não está em condições de valorar adequadamente suas capacidades (ZEĬGARNIK, 1979, p. 108).

Zeı̆garnik (1981) afirma que a enfermidade modifica as atitudes da pessoa em relação ao mundo que a rodeia e a ela mesma. Ocorre, assim, uma debilidade da capacidade de trabalho e uma deterioração de sua produção mental, que podem formar uma parte da síndrome psicopatológica. Funções psicológicas superiores como a atenção, a memória, a abstração e outras, também sofrem alterações e modificam a relação que a pessoa estabelece com a realidade.

Segundo a autora, a alteração da "[...] hierarquia e mediação dos motivos significa a perda da complexa organização da atividade humana. A atividade perde seu traço especificamente humano: de motivada se converte em impulsiva" (ZEĬGARNIK, 1981, p. 161). Tais modificações não se devem a alterações cerebrais, mas estão vinculadas aos motivos, àquilo que incita à ação.

Zeĭgarnik (1979) afirma que é essencial aquilo que adquire sentido vital para o indivíduo. A percepção que o homem tem do mundo depende dos significados e sentidos dados à realidade e aos fatos que ele vivencia.

O significado social da escola, conforme Saviani (2003), seria o de socializar os conhecimentos produzidos pelos homens; mas perguntamos: qual seria o sentido do trabalho para o professor? Entendemos que, nessa perspectiva, deveria ser o de ensinar, vinculado ao processo ensino-aprendizagem, mas não é isso que acontece diante das relações de trabalho em uma sociedade capitalista na qual o homem trabalha para suprir suas necessidades básicas, tais como alimentação e moradia, por exemplo.

Leontiev (1978a) compreende que, nas sociedades primitivas, significado e sentido caminhavam juntos; porém, na sociedade capitalista, com o surgimento da propriedade privada dos meios de produção, da divisão da sociedade em classes e da exploração do homem pelo homem - ou seja, de relações alienadas -, opera-se uma cisão entre o sentido pessoal e o significado social das atividades.

Basso (1998) esclarece que o significado do trabalho do professor é formado pelo seu objetivo de ensinar, de ter como finalidade a apropriação do conhecimento pelo aluno, estando consciente das condições reais e objetivas do processo ensino-aprendizagem; mas se o sentido do trabalho docente tiver como finalidade apenas garantir as necessidades de sobrevivência do professor e se este busca apenas o salário, sem a tomada de consciência de sua participação no processo de produção do gênero humano, haverá cisão com o significado fixado socialmente. De acordo com Basso (1998, p. 27), esse 
[...] significado é entendido como função mediadora entre o aluno e os instrumentos culturais que serão apropriados, visando ampliar e sistematizar a compreensão da realidade e possibilitar objetivações em esferas não cotidianas. Nesse caso, o trabalho alienado do docente pode descaracterizar a prática educativa escolar.

O entendimento dos conceitos de sentido e significado pode contribuir para o entendimento do sentido dado pelo professor à violência e nos permite analisar até que ponto o adoecimento está vinculado a esse aspecto.

\section{O que pensam os professores sobre a violência e adoecimento - a pesquisa realizada}

Participaram do estudo 31 professores do ensino fundamental de uma cidade do norte do Paraná. As informações foram obtidas por meio de questionário aplicado a 21 professores durante um curso de formação e de entrevistas com dez professores que se encontravam readaptados (aqueles afastados das suas funções por decisão médica). Para a seleção dos professores readaptados utilizamos dados fornecidos pelo Núcleo Regional de Ensino da cidade na qual foi realizada a pesquisa. O roteiro foi composto de duas partes: a primeira com dados de identificação e a segunda com dados mais específicos acerca da violência na escola e adoecimento do professor. Esta parte foi composta de 11 questões abertas, abordando aspectos relacionados à concepção que tinham sobre violência, situações de violência vivenciadas na escola, causas da violência, formas de enfrentamento e também relação entre violência e adoecimento do professor. No caso dos professores readaptados, foram incluídas, ainda, duas questões, mais relacionadas ao processo de readaptação: uma quanto ao tempo em que estavam na condição de readaptados e outra sobre o diagnóstico do problema de saúde do professor. O projeto foi aprovado pelo Comitê Permanente de Ética em Pesquisa com Seres Humanos - COPEP.

No tratamento geral das respostas não faremos nenhuma diferenciação entre as informações obtidas nos questionários e nas entrevistas, considerando que o roteiro adotado foi o mesmo. As respostas dos professores, em cada questão, foram agrupadas em categorias. Vamos apresentar alguns dados quantitativos e o agrupamento dessas respostas.

Os professores que participaram da pesquisa apresentaram as seguintes características: $87,09 \%$ eram do sexo feminino; as idades variaram entre 26 e 65 anos, sendo que onze deles $(35,4 \%)$ tinham entre 30 e 45 anos; todos tinham curso superior, com formação em diferentes cursos (Matemática, Geografia, Ciências Sociais, Educação Física, Engenharia Química, Ciências Biológicas, Artes Visuais, Letras, História, Pedagogia, Artes Cênicas, Química), e quatro professores tinham formação em dois cursos; $16(90,3 \%)$ professores fizeram o curso na universidade estadual da cidade na qual foi realizada a pesquisa e, no total, $28(90,3 \%)$ fizeram a graduação em instituição pública; o tempo desde a formação, para a maioria dos professores, variou entre 01 (um) e 40 anos, a saber: entre 16 e 20 anos $-25,8 \%, 26$ a 30 anos - 19,6\%; entre 6 e 10 anos - 16,12\%; e entre 21 e 25 anos $-16,12 \%$, e o tempo de docência, também para a maioria dos professores, assim se distribuiu: entre $16 \mathrm{e}$ 20 anos, com $22,5 \%$, e entre 21 e 25 anos, com $16,12 \%$. Observamos que, somadas outras informações, incluindo os que contavam entre 11 e 35 de tempo de docência, obtivemos o percentual de $77,3 \%$ - ou seja, a maioria dos professores já tinha experiência no magistério.

Quanto aos professores readaptados, o tempo em que estavam nesta condição variou entre 01 (um) e dez anos, e os diagnósticos fornecidos pelos médicos para justificar o afastamento da sala de aula foram os seguintes: hérnia de disco, problemas de visão e depressão, depressão (dois professores), problema de voz, tendinite, fibriomialgia, estresse e ansiedade e deslocamento de quadril. Ao todo, $40 \%$ tinham algum problema diretamente ligado à saúde mental.

Para a análise das respostas sobre as questões da violência e sofrimento do professor, utilizamos a frequência das respostas, uma vez que o mesmo professor poderia dar mais de uma informação sobre a mesma questão. Assim, vamos trabalhar com os seguintes aspectos que foram abordados com os professores: a) conceituação de violência na escola; b) causas da violência na escola; c) tipos de violência vivenciados pelos professores na escola; d) formas de enfrentamento à violência; e) relação entre violência na escola e sofrimento/adoecimento do professor.

\section{a) Conceituação de violência na escola}

Conforme vimos na literatura pesquisada, principalmente em Debarbieux (2001), Charlot (2002), Abramovay e Rua (2002), definir violência é muito complexo e poucos professores apresentaram uma definição explícita sobre essa prática, detendo-se mais em discorrer sobre atos que consideram atos de violência.

Nove respostas citam que a violência remete a atitudes agressivas dentro da escola; oito respostas mencionam falta de respeito nas relações estabelecidas na escola, e várias outras respostas são referentes, principalmente, a fatores exógenos, conforme a concepção de Abramovay e Rua (2002).

Quando os professores mencionam falta de respeito, retomamos o conceito de Charlot (2002), que fala da incivilidade, que é configurada como aquilo que contradiz as regras de boa convivência. Em uma sociedade na qual cada pessoa pensa em si mesma e impera a competição, fica muito difícil estabelecer relações cordiais. A violência, conforme vimos em Sánchez Vázquez (1977), apresenta as características da sociedade e da forma como os homens estão se organizando para transformar a realidade, e o comportamento vivenciado na escola reproduz a relação de dominação presente na sociedade.

Como afirma Heller (1974), a agressividade que permeia as relações humanas é balizada pela fetichização dos homens, que valem muito mais pelo que têm do que pela sua forma de ser. Os homens se tornaram mercadoria e, como tal, têm seu valor guiado pela quantidade de dinheiro que possuem.

As respostas fornecidas sobre a violência na escola vão ao encontro das constatações em pesquisas realizadas por Lobato e Placco (2007) e Loureiro e Queiroz 
(2005), nas quais os entrevistados também conceituam a violência como relacionadas, principalmente, à violência física e à verbal, praticadas de várias formas na escola. Somente em seis casos aparece diretamente o processo ensino-aprendizagem, mencionado em sua relação com a violência na escola, a saber: cobrança da escola e da sociedade sobre o trabalho do professor (duas respostas); violência contra quem tem dificuldade de aprendizagem; comparação entre um professor e outro; falta de condições objetivas para o aluno aprender; e desinteresse por parte dos alunos. Silva (2006) analisa o quanto a violência pode interferir na apropriação do conhecimento e mesmo produzir a exclusão social.

\section{b) Causas da violência na escola}

Em relação às causas da violência na escola, doze entrevistados as atribuíram à desestruturação familiar e doze à desestruturação da sociedade. Os professores entrevistados por Lobato e Placco (2007) e Loureiro e Queiroz (2005) também atribuem à desestruturação familiar os problemas da violência na escola. Esse é um ponto bastante recorrente na literatura: a responsabilização dos pais pelo que ocorre no espaço escolar. Quando se trata das dificuldades de aprendizagem, conforme estudos de Patto (1990) iniciados na década de 1990 e ampliados por pesquisadores como Facci (2004) e Souza (2010), por exemplo, isso fica bastante evidente, e o mesmo ocorre quando se trata de outros enfrentamentos na escola, como é o caso da violência. Fala-se que as famílias são desestruturadas, que não acompanham os filhos na escola, que não dão apoio afetivo, que não educam seus filhos, que não apoiam o trabalho do professor, conforme vimos em respostas fornecidas pelos professores - mas não se questiona por que essas famílias têm este tipo de atitude. A culpa acaba caindo no indivíduo - neste caso, na família.

Cinco professores também relataram como causa da violência na escola a falta de conhecimento, de informação e de leitura, e outros cinco citaram o uso das drogas. Neste caso, professores mencionaram que as drogas são usadas inclusive para marcar algum território (uma resposta); a violência seria decorrente de brigas que ocorrem fora do ambiente escolar. Em uma das respostas foi citada a não compreensão da função social da escola como fator que promove a violência. Podemos dizer que, em um universo de 31 professores, a função social da escola - que, como propõe Saviani (2003), é a de socializar o conhecimento - é pouco referida.

As respostas elencadas pelos professores remeteram o problema mais ao indivíduo, não se referindo às condições histórico-sociais que influenciam a violência presente nas relações escolares. Anser, Joly e Vendramini (2003) também chegaram a esses resultados quando buscaram analisar o conceito de violência entre os professores, mas, quando falavam das causas da violência, estas acabavam recaindo sobre o aluno, como pudemos ver nos dados coletados nesta pesquisa.

Por outro lado, doze respostas citam a desestruturação da sociedade e mesmo a luta de classes (em duas respostas) para explicar a violência na escola. É importante mencionar esse aspecto, pois observamos que muitos professores conseguem sair da instância do particular, do individual, e estabelecem uma relação entre violência na sociedade e violência na escola.

\section{c) Tipos de violência vivenciados pelos professores na escola}

Todos os professores vivenciaram ou sofreram algum tipo de violência na prática pedagógica. Os tipos mais comuns de violência citados foram a violência física e brigas entre alunos (oito respostas), vindo a seguir desrespeito dos alunos quando são cobrados pelos professores (seis respostas) e violência verbal (seis respostas). Tais resultados corroboram o que vem sendo apresentado nos itens anteriores; no entanto, um fato chama a atenção: tanto nos questionários como nas entrevistas esse ponto não parece ter a repercussão que deveria ter, se considerarmos o alarde que a mídia faz quando ocorre algum episódio de violência na escola, principalmente direcionado aos professores.

Outro fator que acaba produzindo violência na escola, conforme mencionam Abramovay e Rua (2002), é o preconceito. Neste estudo foram mencionados o preconceito racial (cinco respostas), o de gênero - neste caso, configurado na homofobia (uma resposta) - e o relativo à deficiência física (uma resposta).

Dois professores mencionaram a burocracia na escola, e outros dois, a desvalorização do trabalho do professor como atos de violência na escola. Somam-se a isso o atraso do aluno e a falta às aulas, a estrutura física deficitária e a violência por parte dos pares por se querer usar metodologias diferenciadas - aspecto pouco mencionado na mídia. É curioso observar que professores estão mais atentos àquilo que é visível - as desavenças, as brigas, as agressões -, assim como se debruçam sobre outros pontos da violência que ultrapassam a análise ou culpabilização do indivíduo e trazem à tona questões relacionadas ao pouco investimento na educação - que resulta, dentre outras consequências, em uma formação deficitária -, ou à falta de condições objetivas para que o processo ensino-aprendizagem tenha êxito.

Quatro professoras citaram situações em que sofreram violência por parte dos pais de alunos, e uma professora comenta ter presenciado um comportamento agressivo de uma coordenadora contra uma professora.

\section{d) Formas de enfrentamento da situação de violência vivenciada}

Interrogamos os professores sobre suas formas de enfrentar a violência, como age a equipe pedagógica nessas situações e outras possibilidades de ação que consideravam importantes. Os sentimentos que demonstraram diante da violência foram os seguintes: indignação (quatro respostas), nervosismo (duas respostas), depressão e desânimo (duas respostas), mal-estar (duas respostas), ficar chocado (uma resposta), sentimento de impotência (uma resposta), medo (uma resposta) e ficar traumatizado (uma resposta). Todos esses sentimentos acabam interferindo na prática pedagógica. 
As formas de enfrentamento do problema mais utilizadas foram a conversa e o aconselhamento, com 15 respostas, vindo a seguir o encaminhamento para a equipe pedagógica da escola, com cinco respostas. Uma professora cita que aproveitou o episódio para fazer um trabalho com a turma toda sobre a violência.

As equipes pedagógicas, segundo as professoras, também utilizam o diálogo, a conversa com o aluno, o aconselhamento (18 respostas), e, ainda, a conversa com a família ou responsáveis. Lobato e Placco (2007) também constaram que o diálogo é a estratégia mais utilizada pelos professores para lidar com a violência na escola. Seis professores mencionaram que a equipe pedagógica também aciona o conselho tutelar, e outros quatro professores disseram ficar paralisados diante da situação.

Quando interrogados sobre outras formas de enfrentamento da violência na escola que poderiam ser utilizadas, quatro professores mencionaram que o trabalho do psicólogo poderia ser útil. A necessidade de um trabalho contínuo também foi citada, por meio de conversas com pais, de debates, de projetos com temas referentes à valorização da vida ou ao uso de drogas, de trabalhos com a escola como um todo. Importante destacar que, de forma geral, em poucas situações foi mencionado o apoio da patrulha escolar para resolver os problemas. Embora - como pudemos ver - em várias situações seja necessário chamar os pais, parece que a escola também tem se mobilizado para enfrentar internamente atos de violência que ocorrem no seu cotidiano. Falamos em enfrentamento por entendermos que, por vezes, a resolução da violência extrapola ações realizadas no interior da instituição - daí concordarmos com um dos professores, que cita a necessidade de políticas sociais que tenham maior investimento na educação.

Não podemos deixar de mencionar que, conforme estudos realizados por Vygotski (1995) e Leontiev (1978b), a personalidade está relacionada às condições sociais, e os vários tipos humanos têm relação com a base material. Assim, no caso do enfrentamento da violência na escola, não basta uma ação direta com os indivíduos, é necessário também investir na transformação das relações que os homens estabelecem na sociedade, o que vai além do aspecto individual, ou mesmo de ações no interior da escola. Não estamos, com isso, desvalorizando este tipo de ação; estamos chamando a atenção para a necessidade de se analisar o contexto social que produz essa violência na escola. Desta forma, as ações devem envolver toda a sociedade e não se ater aos muros da escola.

\section{e) Relação entre violência na escola e adoecimento do professor}

Finalmente chegamos à última questão, que aborda, diretamente, a relação entre violência na escola e sofrimento/adoecimento do professor. Dos 31 professores, 29 compreendem que existe uma relação entre violência e adoecimento do professor. Esses dados, conforme pudemos ver nos parágrafos anteriores, são referendados pelas conclusões obtidas em estudos de Esteve (1999), Levy, Nunes Sobrinho e Souza (2009) e Carlotto e Palazzo (2006). A violência pode ser uma das causas do adoecimento do professor.
Quando interrogamos sobre os tipos de violência/ causas do adoecimento do professor, obtivemos as mais variadas respostas -65 ao todo -, as quais agrupamos conforme descrevemos a seguir. Se analisarmos atos de agressão física e verbal, chegamos a 12 respostas. Pelas respostas a questões anteriores, vimos que os professores consideravam como violência principalmente os atos de violência física ou verbal; no entanto demonstraram que não é somente isso o que causa adoecimento.

Relacionadas diretamente ao ato de ensinar, tivemos oito respostas: desinteresse dos alunos pelas aulas - seis respostas, e não aprendizagem dos alunos - duas respostas. Em relação ao envolvimento da família nas situações de violência que podem contribuir para o adoecimento do professor, tivemos seis respostas: falta de colaboração da família na escola (três respostas); ignorância dos pais em relação a mudanças em seus filhos (uma resposta); problemas pessoais dos alunos que não são resolvidos pelos pais (uma resposta); e violência dos pais contra os professores (uma resposta).

Quando tratamos da situação profissional do professor no dia a dia da prática pedagógica, encontramos 27 respostas: falta de respeito pelo trabalho do professor (cinco respostas); enfrentamento na sala de aula com os alunos (cinco respostas); desrespeito e desacato (cinco respostas); ter de lidar com muitos problemas, com alunos com características diferenciadas (três respostas); sobrecarga de trabalho (duas respostas); excesso de alunos em sala de aula (duas respostas); frustração por não conseguir ensinar (duas respostas); cobrança da escola e da sociedade sobre o trabalho do professor (uma resposta); falta de apoio por parte da equipe pedagógica (uma resposta); ser obrigado a aprovar o aluno mesmo quando ele não tem condições (uma resposta). O maior número de ações mencionadas refere-se, mais particularmente, à vida do professor, ao cotidiano da escola, e não a atos de violência física ou verbal em si. Podemos considerar que, do ponto de vista dos professores, o que provoca adoecimento é a violência simbólica, aquela que não está claramente explícita.

Conforme Basso (1998), as condições objetivas para ensinar apresentadas pelos professores podem contribuir para a ruptura entre sentido e significado da prática do professor. Como ele pode continuar hierarquizando os motivos da sua atividade referente ao ato de ensinar se ele sente que a própria sociedade desvaloriza o seu trabalho?

Nas respostas dos professores fica evidenciado o quanto a "desprofissionalização" - conforme o entendimento de Oliveira, D. (2004) - e o desmantelamento das relações de trabalho imposto historicamente pelo sistema de produção têm adentrado a escola e proletarizado o trabalho do professor.

O esvaziamento do trabalho, conforme defende Facci (2004), a pouca valorização da atividade pedagógica, as relações de trabalho e as transformações das políticas educacionais - que cada vez mais descaracterizam o ato de ensinar como aquele que leva o aluno a se apropriar do conhecimento, guiado por um professor que deveria 
estar humanizado (no sentido de ter acesso aos bens culturais mais desenvolvidos pelos homens) - contribuem para esse adoecimento do professor. Nem todos adoecem ou se afastam do trabalho, mas todos os professores pesquisados analisam que existe relação entre adoecimento e violência na escola.

De forma geral, as respostas que os professores deram a essa questão nos causaram certa estranheza, pois nossa hipótese inicial era a de que a violência - principalmente a física e a verbal - fosse um dos grandes problemas vividos pelos professores na escola. O desenvolvimento do trabalho parece revelar que a violência decorrente da precarização do trabalho também é um dos grandes problemas da escola, embora não seja o único e (talvez) nem o maior.

\section{Considerações finais}

Os dados da pesquisa nos levam a várias considerações. Uma das mais importantes é a que permite concluir que, diferentemente do que é divulgado na mídia - que faz sensacionalismo quando ocorre algum episódio de violência, principalmente de aluno com professor -, o que produz o adoecimento do professor não são somente os atos de violência física. Se nos basearmos nos dados sobre os tipos de violência que causam adoecimento do professor, a partir das entrevistas realizadas com os dez professores readaptados, veremos que o tipo de violência que mais causa adoecimento é a falta de respeito pelo trabalho do professor (quatro respostas), vindo a seguir o enfrentamento em sala de aula (três respostas). Além disso, outras respostas foram mencionadas - como a falta de apoio da sociedade (uma resposta) e ter que lidar com muitos problemas, com alunos com características diferenciadas (uma resposta). Sobre os motivos que provocam o adoecimento do professor, tivemos uma resposta que fala da indisciplina, uma que considera a violência verbal e uma que fala do desrespeito e desacato ao professor.

Como pudemos constatar, o que mais contribui para o adoecimento do professor é a violência simbólica configurada por Charlot (2002) como uma violência da escola, por Abramovay e Rua (2002) como decorrente de situações em que os professores, por exemplo, são agredidos na transmissão dos conhecimentos devido ao desinteresse dos alunos, e por Lobato e Placco (2007) como desrespeito ao professor.

Consideramos que as violências mencionadas pelos professores na última questão apresentada denotam muito bem o sentimento de desânimo que eles muitas vezes manifestam na atividade docente. Zel̆garnik $(1979,1981)$ analisa que a enfermidade lesiona a personalidade como um todo e faz com que o indivíduo modifique a sua atitude em relação ao meio, e mesmo em relação ao trabalho. $\mathrm{Na}$ hierarquização dos motivos, como esse professor pode ser motivado para o ensino, para a condução da apropriação dos conhecimentos, se condições objetivas e subjetivas não contribuem para isso? Interrogamos, ainda: o adoecimento do professor não seria uma forma de contraposição ao processo de alienação e de submissão aos ditames do capital que produz uma escola que nem sempre consegue ensinar? Que produz uma escola que reproduz a ideolo- gia dominante de não permitir que todos tenham acesso ao conhecimento? Seria o adoecimento uma forma de o professor enfrentar o esvaziamento do conhecimento e do trabalho, conforme aponta Facci (2004)?

Se levarmos em conta a análise de Oliveira, D. (2004) - que fala da pauperização do trabalho do professor como decorrente do próprio sistema de produção que vem sendo configurado continuamente para manter vivo o capitalismo -, podemos compreender que a personalidade desse professor que está em sofrimento psíquico está sendo influenciada diretamente pelas suas condições de trabalho, as quais não são satisfatórias, conforme relato dos professores. A violência - física ou verbal - que ocorre não pode ser banalizada, mas o pouco investimento dado à educação fica implícito nas falas dos professores. É principalmente essa violência subliminar que causa adoecimento.

Podemos dizer que a violência contra os professores do Estado do Paraná, citada no início do artigo - muito além de uma violência simbólica - foi, sim, uma violência física. O ocorrido em abril de 2015 demonstra bem o quanto as relações de trabalho estão ficando complexas e o quanto os trabalhadores estão perdendo seus direitos para manter o capital da forma que vem ocorrendo nos últimos anos. Vivemos, de fato, um acirramento nas relações de trabalho, com uma desvalorização ampla daqueles que muitas vezes precisam vender a única coisa que têm: a força de trabalho.

O processo de alienação está presente na atividade do professor, e este, que tem a função social de ensinar, a partir do momento em que não mais realiza esta função não encontra o motivo que impulsiona sua atividade, conforme estruturação da personalidade defendida por Leontiev (1978a, 1978b). A atividade pedagógica realizada nestas circunstâncias vitima, adoece, faz sofrer e impossibilita a realização dos sujeitos no trabalho, além de inviabilizar o desenvolvimento desses sujeitos em direção à humanização. Diante deste contexto, interrogamos: como superar a violência na escola, se vivemos em uma sociedade violenta? Não basta buscar as causas. Temos que entender o estágio atual em que se encontra a sociedade capitalista, para então podermos compreender esse fato e encontrar formas de enfrentamento no âmbito do processo educativo. A violência, como afirma Costa (2014), tem sua gênese nas relações sociais de produção. "Dessa forma, a violência que se manifesta nas escolas é entendida por nós como uma expressão das relações violentas que se estabelecem fora dela e, portanto, a superação da violência exige a superação das condições sociais que a produzem" (COSTA, 2014, p. 10).

Conforme a análise de Oliveira, E. e Martins (2007), a violência na escola é decorrente da desigualdade de classes sociais antagônicas, da imposição de regras coletivas que não fazem sentido para os alunos, ou mesmo da repetição de experiências vivenciadas pelos alunos junto a suas famílias; no entanto as autoras comentam que essa violência começa quando os alunos não têm a possibilidade de acesso aos conhecimentos:

Podemos entrever os desdobramentos que poderiam ser con- 
cebidos através da dupla escola/violência: há "a escola da violência" construída pela sociedade que mantém e fomenta a violência estrutural que, por sua vez, difunde as demais formas de violência que os indivíduos vão aprendendo e assimilando em seu cotidiano, ora sutilmente, ora abertamente. Tem-se a "violência na escola" que, como foi demonstrado, acontece através da troca de agressões físicas e verbais entre alunos ou alunos e professores assim como também existe a "violência da escola", a escola como reprodutora da ideologia dominante e das desigualdades sociais, empareda professores e alunos em suas normas, regras e leis, impedindo-os de movimentar-se para direcionarem-se de maneira autônoma e, sobretudo, transformadora. Assim, a escola (sociedade), que ensina e pratica a violência, tem como sua representante a instituição escolar, que vivencia e exerce também suas violências (OLIVEIRA, E.; MARTINS, 2007, p. 97).

Por outro lado, conforme a lógica dialética, que trabalha com as contradições, essa mesma escola que pode violentar os alunos também pode emancipá-los. Nessa compreensão, em conformidade com a linha defendida por Saviani (2003), pela qual a função da escola é socializar os conhecimentos construídos pelos homens, e com a proposição de Vigotski (2000) de que a aprendizagem promove desenvolvimento, compreendemos que a escola tem diante de si a tarefa de trabalhar com os conhecimentos científicos de modo a formar uma segunda natureza nos alunos, provocando o desenvolvimento das funções psicológicas superiores e, desta forma, ampliando a compreensão que os alunos possam ter da realidade. Nesse encaminhamento, o professor também precisa ter sentido em sua prática em direção à apropriação do conhecimento por parte dos alunos; mas para isso ele também tem que se humanizar e adquirir condições efetivas para ter acesso ao conhecimento e organizar a prática docente em relação à instrumentalização dos alunos.

Quanto à violência na escola, concordamos com as ideias de Chauí (2000) e Sánchez Vázquez (1977, p. 404) e compreendemos, como este último pesquisador, que "só ao deixar de ser violenta, a práxis social terá uma dimensão autenticamente humana". Assim, entendemos que na escola esse fato precisa ser enfrentado analisando-se as condições materiais que o produzem, e que se deve trabalhar em prol da coletividade. Oliveira, D. (2004) defende que a participação dos docentes e da comunidade na elaboração de políticas sociais deve ser uma exigência da gestão escolar, que deve entender a escola como um espaço de política e de trabalho, tudo isso aliado à luta pelo reconhecimento do trabalho do professor. Entendemos que tais ações devem ser direcionadas também para a superação do adoecimento do professor, e que esta questão não é de âmbito individual, uma vez que o indivíduo é constituído nas relações sociais. Esse entendimento é fundamental para aqueles profissionais que lidam com esse adoecimento, entre eles o psicólogo.

Em nosso entendimento, não seria um caminho profícuo tratar desse adoecimento encaminhando um professor somente para atendimento clínico, individual, sem considerar as relações estabelecidas na escola, as quais são matizadas pela forma como a sociedade está orga- nizada. Esse adoecimento, quando vinculado às dificuldades vivenciadas na escola, deve ser analisado como multideterminado, numa relação dialética entre o indivíduo e a sociedade. Como analisa Oliveira, B. (2005), é na relação entre o particular (no caso, as relações escolares) e a sociedade que devemos analisar os fatos humanos.

Se os professores vêm adoecendo com maior frequência em virtude de sua atividade ocupacional, é necessário compreender esse fenômeno e dar respostas à realidade que se apresenta diante da academia, e os conhecimentos da Psicologia podem auxiliar nesta empreitada. Com a mesma urgência, é preciso ampliar os trabalhos sobre saúde/doença do professor a partir dos pressupostos do Materialismo Histórico e Dialético e da Psicologia Histórico-Cultural.

\section{Informações sobre a autora:}

\section{Marilda Gonçalves Dias Facci \\ (iD) http://orcid.org/0000-0001-7443-490X \\ (9) ttp://lattes.cnpq.br/2222738235813129}

Possui graduação em Psicologia pela Universidade Estadual de Maringá (1986), mestrado em Educação pela Universidade Estadual Paulista Júlio de Mesquita Filho (1998); doutorado em Educação Escolar pela faculdade de Ciências e Letras de Araraquara - UNESP (2003) e Pós-doutorado pelo Instituto de Psicologia da USP e PósDoutorado na Universidade Federal de Mato Grosso do Sul.

\section{Como citar este artigo:}

\section{ABNT}

FACCI, Marilda Gonçalves Dias. O adoecimento do professor frente à violência na escola. Fractal: Revista de Psicologia, Niterói, v. 31, n. 2, p. 130-142, maio/ago. 2019. https://doi.org/10.22409/19840292/v31i2/5647

\section{APA}

Facci, M. G. D. (2019). O adoecimento do professor frente à violência na escola. Fractal: Revista de Psicologia, 31(2), 130142. doi:10.22409/1984-0292/v31i2/5647

\section{Referências}

ABRAMOVAY, Miriam; RUA, Maria das Graças. Violências nas escolas: versão resumida. Brasília: UNESCO / Instituto Ayrton Senna / UNAIDS / Banco Mundial / USAID / Fundação Ford / CONSED / UNDIME, 2002.

ANSER, Maria Aparecida Carmona Ianhes; JOLY, Maria Cristina Rodrigues Azevedo; VENDRAMINI, Claudete Maria Medeiros. Avaliação do conceito de violência no ambiente escolar: visão do professor. Psicologia: Teoria $e$ Prática, São Paulo, v. 5, n. 2, p. 67-81, 2003. Disponível em: http://editorarevistas.mackenzie.br/index.php/ptp/article/ view/1191/889. Acesso em: 24 nov. 2014.

ASSUNÇÃO, Ada Ávila; OLIVEIRA, Dalila Andrade. Intensificação do trabalho e saúde dos professores. Educação e Sociedade, Campinas, v. 30, n. 107, p. 349-372, ago. 2009. http://dx.doi.org/10.1590/S0101-73302009000200003 
BASSO, Itacy Salgado. Significado e sentido do trabalho docente. Cadernos CEDES, Campinas, v. 19, n. 44, p. 19-32, abr. 1998. http://dx.doi.org/10.1590/S0101-32621998000100003

BRASIL lidera ranking de violência contra professor. Jornal do Brasil, Rio de Janeiro, p. 1, 15 out. 2014.

BENEVIDES-PEREIRA, Ana Maria T. et al. O trabalho docente e o burnout: um estudo em professores paranaenses. In: CONGRESSO NACIONAL DE EDUCAÇÃO DA PUCPR EDUCERE, 8, 2008, Paraná. Anais... Paraná, 2008. p. 4870 4884.

CARLOTTO, Mary Sandra; PALAZZO, Lílian dos Santos. Síndrome de burnout e fatores associados: um estudo epidemiológico com professores. Cadernos de Saúde Pública, Rio de Janeiro, v. 22, n. 5, p. 1017-1026, maio 2006. http:/ dx.doi.org/10.1590/S0102-311X2006000500014

CHARLOT, Bernard. A violência na escola: como os sociólogos franceses abordam essa questão. Revista Sociologias, Porto Alegre, n. 8, p. 432-443, dez. 2002. http://dx.doi.org/10.1590/ S1517-45222002000200016

CHAUÍ, Marilena. Convite à Filosofia. São Paulo: Ática, 2000. Disponível em: http://www.filosofia.seed.pr.gov.br/arquivos/ File/classicos_da_filosofia/convite.pdf. Acesso em: 27 nov. 2012.

CODO, Wanderley (Org.). Educação: carinho e trabalho Burnout, a síndrome da desistência do educador, que pode levar à falência da educação. Rio de Janeiro: Vozes, 1999.

COSTA, Mariana Lins e Silva. Violência nas escolas: contribuições da Psicologia Histórico-Cultural para seu enfrentamento na educação. 2014. Dissertação (Mestrado) Universidade Estadual de Maringá, Maringá, 2014.

DEBARBIEUX, Éric. A violência na escola francesa: 30 anos de construção social do objeto (1967-1997). Revista Educação e Pesquisa, São Paulo, v. 27, n. 1, p. 163-193, 2001. http:/ dx.doi.org/10.1590/S1517-97022001000100011

ESTEVE, José Manuel. O mal-estar docente: a sala de aula e a saúde dos professores. Bauru, SP: EDUSC, 1999.

FACCI, Marilda Gonçalves Dias. Valorização ou esvaziamento do trabalho do professor? Um estudo crítico-comparativo da teoria do professor reflexivo, do construtivismo e da psicologia vigotskiana. Campinas: Autores Associados, 2004. Coleção Formação de Professores.

GOMES, Candido Alberto; PEREIRA, Marlene Monteiro. A formação do professor em face das violências das/nas escolas. Cadernos de Pesquisa, São Paulo, v. 39, n. 136, p. 201-224, apr. 2009. http://dx.doi.org/10.1590/S010015742009000100010

HELLER, Agnes. Instinto, agressividad y caráter. Barcelona: Península, 1994.

LEONTIEV, Alexis. N. Las necesidades y los motivos de la actividade. In: SMIRNOV, Anatoli. et al. Psicologia. México: Grijalbo, 1969. p. 341-352

LEONTIEV, Alexis N. O desenvolvimento do psiquismo. Lisboa: Livros Horizonte, 1978a.

LEONTIEV, Alexis N. Actividad, conciencia y personalidad. Buenos Aires: Ediciones Ciencias del Hombre, 1978b.
LEVY, Gisele Cristine Tenório de Machado; NUNES SOBRINHO, Francisco de Paula; SOUZA, Carlos Alberto Absalão de. Síndrome de burnout em professores da rede pública. Produção, São Paulo, v. 19, n. 3, p. 458-465, 2009. http://dx.doi.org/10.1590/S0103-65132009000300004

LOBATO, Vivian da Silva; PLACCO, Vera Maria Nigro de Souza. Concepções de professores sobre questões relacionadas à violência na escola. Psicologia da Educação, São Paulo, v. 24, p. 73-90, jun. 2007. Disponível em: http:// pepsic.bvsalud.org/scielo.php?script=sci_pdf\&pid=S1414$69752007000100006 \& \operatorname{lng}=p t \& n r m=i s o \&$ tlng=pt. Acesso em: 30 set. 2014.

LOUREIRO, Ana Carla Amorim Moura; QUEIROZ, Sávio Silveira de. A concepção de violência segundo atores do cotidiano de uma escola particular: uma análise psicológica. Revista Psicologia, Ciência e Profissão, Brasília, v. 25, n. 4, p. 546-557, 2005. http://dx.doi.org/10.1590/S141498932005000400005

MOSQUERA, Juan José Mouriñ; STÖBAUS, Claus Dieter. O mal-estar na docência: causas e consequências. Educação, Porto Alegre, n. 31, p. 139-146, 1996.

OLIVEIRA, Betty. A dialética do singular-particular-universal. In: ABRANTES, Angelo Antonio; SILVA, Nilma Renildes da; MARTINS, Sueli Terezinha Ferreira. (Org.). Método históricosocial na psicologia social. Petrópolis, RJ: Vozes, 2005. p. $25-$ 51.

OLIVEIRA, Dalila Andrade. A reestruturação do trabalho docente: precarização e flexibilização. Educação \& Sociedade, Campinas, v. 25, n. 89, p. 1127-1144, dez. 2004. http://dx.doi. org/10.1590/S0101-73302004000400003

OLIVEIRA, Érika Cecília Soares; MARTINS, Sueli Terezinha Ferreira. Violência, sociedade e escola: da recusa do diálogo à falência da palavra. Psicologia e Sociedade, Porto Alegre, v. 19, n. 1, p. 90-98, abr. 2007. http://dx.doi.org/10.1590/S010271822007000100013

PATTO, Maria Helena Souza. A produção do fracasso escolar: histórias de submissão e rebeldia. São Paulo: T. A. Queiroz, 1990.

SÁNCHEZ VÁZQUEZ, Adolfo. Filosofia da Práxis. 2. ed. Rio de Janeiro: Paz e Terra, 1977.

SANTOS, Diego Augusto dos. Contribuições da Psicologia Histórico-Cultural para a compressão do adoecimento e sofrimento psíquico de professores. 2014. Dissertação (Mestrado) - Universidade Estadual de Maringá, Maringá, 2014.

SAVIANI, Dermeval. Pedagogia histórico-crítica: primeiras aproximações. 8. ed. Campinas: Cortez, 2003.

SÈVE, Lucien. Marxismo e teoria da personalidade. Lisboa: Livros Horizontes, 1979. v. 3.

SILVA, Nilma Renildes da. Relações sociais para superação da violência no cotidiano escolar e processos formativos de professores. 2006. Tese (Doutorado) - Pontifícia Universidade Católica - São Paulo, 2006.

SPOSITO, Marilia Pontes. Um breve balanço da pesquisa sobre violência escolar no Brasil. Revista Educação e Pesquisa, São Paulo, v. 27, n. 1, p. 87-103, 2001. http://dx.doi.org/10.1590/ S1517-97022001000100007 
SOUZA, Marilene Proença Rebello de. Psicologia Escolar e políticas públicas em Educação: desafios contemporâneos. Em Aberto, v. 23, n. 83, p. 129-149, 2010.

VIGOTSKI, Lev Semionovitch. S. A construção do pensamento e da linguagem. São Paulo: Martins Fontes, 2000.

VYGOTSKI, Lev Semionovitch. Obras escogidas: problemas del desarrollo de la psique. Madrid: Visor, 1995. v. 3.

ZEĬGARNIK, Bliuma Vul'fovna. Introducción a la patopsicologia. La Habana: Científico Técnica, 1979.

ZEĬGARNIK, Bliuma Vul'fovna. Psicopatologia. Madrid: Akal, 1981. 